\title{
IMPLEMENTASI PROGRAM ADIWIYATA DALAM PEMBENTUKAN KARAKTER PEDULI LINGKUNGAN DI SD MUHAMMADIYAH BODON KOTAGEDE
}

\author{
Endah Riyanti, Ika Maryani \\ PGSD, Universitas Ahmad Dahlan \\ endahriyanti33@gmail.com
}

\begin{abstract}
This study aims to determine the planning, implementation, and evaluation of the adiwiyata program in shaping the character of caring for the environment and to find out supporting factors and obstacles in the implementation of the adiwiyata program in shaping the character of the care for the environment in SD Muhammadiyah Bodon Kotagede. This type of research is a qualitative descriptive study. Data collection methods are done through interviews, observation, and documentation. Research subjects were the principal, the adiwiyata team, teachers, and students. The validity of the data uses triangulation techniques. Analysis techniques using data collections, data reduction, data presentation and drawing conclusions. The results showed that the implementation of the adiwiyata program in shaping the character of caring for the environment had been integrated in policies that were environmentally friendly and integrated in each subject. The integration was socialized to all school members to create an environmentally friendly school agreement. The supporting factors for the implementation of the adiwiyata program are the beautiful school environment, good cooperation between the schools, adequate budget, and environmentally friendly supporting facilities that support the implementation of the adiwiyata program. Factors inhibiting the implementation of the adiwiyata program include that there are still students who are not yet aware of understanding the concept of being environmentally minded and still lacking land for the process of growing green plants.
\end{abstract}

Keywords: adiwiyataenvironmental care, character building

\begin{abstract}
ABSTRAK
Penelitian ini bertujuan untuk mengetahui perencanaan, pelaksanaan dan evaluasi program adiwiyata dalam pembentukan karakter peduli lingkungan dan untuk mengetahui faktor pendukung dan penghambat implementasi program adiwiyata dalam pembentukan karakter peduli lingkungan di SD Muhammadiyah Bodon Kotagede. Jenis penelitian ini adalah penelitian deskriptif kualitatif. Metode pengumpulan data dilakukan melalui wawancara, observasi dan dokumentasi. Subjek penelitian adalah kepala sekolah, tim adiwiyata, guru dan siswa. Keabsahan data menggunakan triangulasi teknik. Teknik analisis data menggunakan pengumpulan data, reduksi data, penyajian data dan penarikan kesimpulan. Hasil penelitian menunjukan bahwa implementasi program adiwiyata dalam pembentukan karakter peduli lingkungan sudah terintegrasi pada kebijakan yang berwawasan lingkungan dan terintegrasi dalam masing-masing mata pelajaran, kemudian pengintegrasian disosialisasikan kepada seluruh warga sekolah untuk menciptakan kesepakatan sekolah yang berwawasan lingkungan. Faktor pendukung terlaksananya program adiwiyata yaitu lingkungan sekolah yang asri, kerja sama yang baik antara pihak sekolah, anggaran yang
\end{abstract}


memadai dan sarana pendukung yang ramah lingkungan sehingga mendukung pelaksanaan program adiwiyata. Faktor penghambat pelaksanaan program adiwiyata antara lain masih ada peserta didik yang belum sadar dalam memahami konsep berwawasan lingkungan dan masih kurang lahan untuk proses menanam tumbuhan hijau.

Kata kunci: adiwiyata, peduli lingkungan, pendidikan karakter

\section{PENDAHULUAN}

Pendidikan merupakan salah satu sarana yang digunakan manusia untuk mengembangkan potensinya. Manusia adalah makhluk hidup yang mampu bertanggung jawab dengan cara mengenal, menghayati serta melaksanakan nilai-nilai moral. Sesuai dengan pendapat Widyaningrum (2016 :108) pendidikan memiliki peran yang penting bagi manusia. Pendidikan berperan dalam membentuk kemampuan, kepribadian dan watak yang bermartabat dengan cara menanamkan nilai-nilai pendidikan terhadap generasi penerus bangsa. Penanaman nilai-nilai pendidikan terhadap generasi penerus bangsa harus memiliki tujuan pendidikan. Tujuan pendidikan yang dicapai yaitu melalui proses pendidikan. Pendidikan yang paling dasar yaitu sekolah dasar. Pada usia ini anak sangat aktif untuk mempelajari apa saja yang ada pada lingkungan, dorongan untuk mengetahui dan berbuat terhadap lingkungan sangat besar.

Peserta didik akan secara aktif mengembangkan potensi dirinya untuk memiliki kekuatan spiritual keagamaan, pengendalian diri, kepribadian, akhlak mulia, serta keterampilan yang diperlukan dirinya, masyarakat, bangsa dan Negara. Tentunya tujuan pendidikan tidak lepas dari lingkungan pendidikan. Pendidikan lingkungan merupakan salah satu faktor yang sangat penting untuk meminimalisasi kerusakan pada lingkungan dan merupakan salah satu alternatif solusi yang efektif dalam meningkatkaan pengetahuan dan pemahaman masyarakat terhadap pelestarian fungsi lingkungan. Pendidikan dan lingkungan mempelajari interaksi antara makhluk hidup ataupun interaksi antara makhluk hidup dengan lingkungannya (Rohman, 2009:195). Pelestarian lingkungan hidup merupakan upaya untuk melindungi lingkungan yang ditimbulkan oleh suatu kegiatan makhluk hidup yang kurang peduli terhadap pengelolaan lingkungan.

Pengelolaan lingkungan hidup merupakan suatu kegiatan yang dilakukan guna menjaga dan melestarikan pengelolaan lingkungan dengan mencakup beberapa aspek diantaranya pemanfaatan, pengaturan, pemeliharaan, pemulihan, pengendalian, pembinaan, serta upaya pelestarian lingkungan hidup yang dilaksanakan secara integratif untuk melestarikan fungsi lingkungan hidup (Hamzah, 2013:23). Kurangnya rasa peduli lingkungan mengakibatkan terjadinya eksploitasi dan kerusakan lingkungan. Untuk mengatasi hal tersebut, salah satunya dengan upaya menanamkan dan mengenalkan rasa peduli lingkungan melalui jalur pendidikan, tidak terkecuali pendidikan sekolah dasar (Maryani:2018) Pengelolaan lingkungan hidup tidak hanya menyangkut tentang pemanfaatan tetapi juga upaya untuk menyadarkan manusia terhadap kepeduliannya dalam menjaga dan melestarikan kualitas lingkungan. menyadarkan manusia yang kurang memahami kualitas lingkungan yaitu dengan penanaman dan pemahaman yang diterapkan melalui penanaman pendidikan karakter.

Penanaman karakter sejak dini dapat menjadi dasar yang kuat bagi penanaman karakter peduli lingkungan. Karakter akan berkembang jika mendapatkan pengalaman belajar dari lingkungan di sekitarnya. Undang-undang RI No.32 Tahun 2009 tentang perlindungan dan pengelolaan lingkungan hidup menambahkan salah satu cara untuk menanamkan karakter peduli lingkungan melalui kesehatan lingkungan sekolah. Sekolah merupakan salah satu tempat dalam membentuk karakter sehingga Peserta didik memiliki 
kepribadian yang lebih baik. Karakter peduli lingkungan dapat ditanamkan berdasarkan kurikulum sekolah maupun program-program yang sudah direncanakan sekolah. Program yang direncanakan salah satunya adalah program adiwiyata. Kementrian Negara Lingkungan Hidup pada Tahun 2006 menyatakan bahwa program adiwiyata yaitu Program yang bertujuan untuk mendorong dan membentuk sekolah-sekolah di Indonesia agar dapat turut melaksanakan upaya-upaya pemerintah menuju pelestarian lingkungan dan pembangunan berkelanjutan bagi kepentingan generasi yang akan datang. Sekolah adiwiyata adalah sekolah yang memanfaatkan lingkungan sebagai sumber dan tempat kegiatan belajar mengajar memperhatikan kondisi lingkungan sekolah yang ramah terhadap lingkungan serta mendukung pelestarian dan penyelamatan lingkungan hidup sehingga menjadi sekolah yang hijau dengan tertata rapi, indah, rindang dan bersih (Widodo:2017). Upaya tersebut mengajarkan kepada peserta didik di sekolah untuk lebih akrab dengan lingkungan serta dapat menjadikan lingkungan sebagai sumber belajar.

Pendidikan lingkungan hidup di sisi lain merupakan salah satu implementasi wajib bagi sekolah guna membentuk karakter peduli lingkungan. SD Muhammadiyah Bodon Kotagede, terlihat beberapa penerapan pendidikan lingkungan hidup yang sudah terlaksana terbukti sudah meraih adiwiyata. SD Muhammadiyah Bodon merupakan salah satu SD Unggulan yang ada di kota Yogyakarta yang memiliki banyak prestasi salah satunya pada tahun 2013 mendapatkan penghargaan sebagai sekolah adiwiyata tingkat nasional. SD Muhammadiyah Bodon Kotagede, telah menerapkan program adiwiyata dilihat dari lingkungan sekolah yang bersih dan asri.

Terlihat dari visi SD Muhammadiyah Bodon yaitu "Terwujudnya lembaga pendidikan dasar yang terdepan dalam berbagai prestasi, berakhlak mulia, kreatif, peduli pada lingkungan hidup dan berwawasan islami." Selain itu juga sekolah terdapat beberapa misi yaitu : melaksanakan Pembelajaran Aktif Inovatif Kreatif Efektif dan menyeenangkan (PAIKEM), Membiasakan perilaku bersih dan sehat, meningkatkan kesiapsiagaan menghadapi bencana, melaksanakan aktualisasi potensi, bakat, minat olahraga dan seni, melaksanakan kepedulian terhadap lingkungan hidup. Terlihat dari hal tersebut menjadikan sekolah yang berwawasan lingkungan hidup, yang merupakan wujud dari pelaksanaan program adiwiyata. Selain memiliki kebijakan yang berwawasan lingkungan, sekolah juga memiliki kurikulum berbasis lingkungan. Pelaksanaan kurikulum berbasis lingkungan dengan mengajarkan kepada peserta didik untuk melakukan kegiatan pemebelajaran tentang pengelolaan lingkungan.

Peserta didik tidak hanya belajar secara teori saja namum juga dengan praktek yaitu dengan menjaga kebersihan kelas. Kegiatan kebersihan kelas dilakukan setiap pagi diawali dengan kegiatan membersihkan kelas oleh regu piket yang sudah terbentuk setiap kelasnya. Regu piket juga bertanggung jawab menjaga kebersihan kelas selama satu hari penuh dan peserta didik yang tidak terjadwal piket tetap harus menjaga kebersihan kelas. Meskipun masih ada peserta didik yang beranggapan bahwa kebersihan sekolah merupakan tugas tanggung jawab petugas kebersihan sekolah. Sekolah membudayakan kebersihan lingkungan sebagai tanggung jawab seluruh warga sekolah, bukan hanya tanggung jawab petugas kebersihan sekolah. Seluruh peserta didik belajar untuk merawat tanaman yang ada di lingkungan sekolah. Namun belum diketahui implementasi terkait program adiwiwyata dalam pembentukan karakter peduli lingkungan di sekolah tersebut. Dengan menerapkan pendidikan karakter peduli lingkungan peseerta didik akan lebih mudah mengaplikasikan nilai-nilai yang diterimanya dalam bentuk kreativitas. 


\section{METODE PENELITIAN}

Jenis penelitian yang digunakan adalah penelitian deskriptif kualitatif. Pengumpulan data dilakukan dengan teknik wawancara, observasi dan dokumentasi. Subjek penelitian adalah Kepala sekolah, 2 guru atau tim adiwiyata, 2 peserta didik. Objek penelitian adalah komponen program adiwiyata kebijakan berwawasan lingkungan, kegiatan paertisipatif, pelaksanaan kurikulum berbasis lingkungan, pengelolaan sarana prasarana ramah lingkungan. Penelitian ini dilakukan di SD Muhammadiyah Bodon Kotagede. Penelitian ini dilaksanakan pada bulan Juli-Agustus 2019. Observasi dalam penelitian ini berupa pengamatan program sekolah dan proses pembelajaran dalam melaksanakan pendidikan karakter peduli lingkungan. wawancara yang digunakan dalam penelitian ini adalah wawancara semiterstruktur. Wawancara dalam penelitian ini digunakan untuk mengetahui implementasi program adiwiyata dalam pembentukan karakter peduli lingkungan. informan wawancara dalam penelitian ini adalah kepala sekolah, tim adiwiyata, guru dan peserta didik. Keabsahan data yang digunakan peneliti adalah triangulasi teknik dan triangulasi sumber. Teknik analisis data yang digunakan yaitu pengumpulan data, reduksi data, penyajian data dan penarikan kesimpulan.

\section{HASIL DAN PEMBAHASAN}

Hasil Penelitian

1. Perencanaan implementasi program adiwiyata di SD Muhammadiyah Bodon Kotagede

SD Muhammadiyah Bodon Kotagede surah meraih Adiwiyata sejak tahun 2013 dan program tersebut masih berjalan sampai sekarang dan semakin baik dari tahun ke tahun. Beradasarkan hasil penelitian perencanaan program adiwiyata dalam pembentukan karakter peduli lingkungan tersebut yaitu dengan mengintegrasikan melalui visi dan misi sekolah yaitu ada kebijakan berwawasan lingkungan dan disosialisasikan kepada seluruh warga sekolah agar mempunyai komitmen bersama. Selain merumuskan visi dan misi sekolah juga sudah merancang struktur kurikulum yang berkaitan dengan lingkungan hidup yang didalamnya mencakup materi pelaksanaan lingkungan hidup dan sudah terintegrasi pada semua mata pelajaran dan sekolah menetapkan ketuntasan miniman pembelajaran yang berkaitan dengan lingkungan hidup yaitu 75 untuk semua mata pelajarann baik mata pelajaran wajib ataupun muatan lokal. Sekolah untuk mengoptimalkan perencanaan pendidikan lingkungan hidup yaitu dengan melakukan rapat rutin kegiatan tersebut dilaksanakan agar sekolah mengetahui program tersebut berjalan baik atau tidak dan jika ada kendala dalam pelaksanaan dapat diselesaikan secara bersama-sama. Sekolah juga menempatkan anggaran untuk upaya perlindungan dan pengelolaan tersebut dalam RKAS.

2. Pelaksanaan implementasi program adiwiyata di SD Muhammadiyah Bodon Kotagede

Sekolah yang peduli lingkungan harus diimbangi dengan wawasan mengenai lingkungan. salah satu cara meningkatkan wawasan tersebut adalah dengan melaksanakan kurikulum berbasis lingkungan. SD Muhammadiyah Bodon melaksanakan dengan mengintegrasikan pendidikan lingkungan pada kurikulum 2013 sehingga pendidikan lingkungan hidup tidak menjadi pelajaran tersendiri atau berdiri sendiri. Guru dalam pelaksanaan pendidikan lingkungan hidup diintegrasikan pada mata pelajaran dan mengembangkan rancangan pembelajaran dengan menerapkan metode dan strategi pembelajaran yang melibatkan peserta didik untuk aktif yaitu salah satunya dengan mengajak peserta didik untuk belajar diluar kelas melakukan pengamatan terhadap lingkungan yang ada disekitar sekolah. Guru mengembangkan isu lokal maupun global dalam pembelajaran, contohnya guru menjelaskan tentang makanan sehat, ataupun 
tanaman-tanaman yang ada disekitar lingkungan sekolah. Upaya-upaya tersebut untuk menanamkan nilai karakter peduli lingkungan. peserta didik juga diberikan upaya untuk menjalankan tugas piket masing-masing kelas secara bergiliran sesuai jadwal yang sudah disepakati.

Peserta didik menjaga lingkungan sekolah seperti menyiram tanaman dan memberi pupuk hal ini dilakukan agar peserta didik tahu bahwa keindahan dan kebersihan sekolah adalah tugas seluruh warga sekolah bukan hanya tugas penjaga kebirsihan sekolah. Pengelolaan lingkungan berbasis partisipatif juga dilakukan peserta didik dalam upaya pembentukan karakter peduli lingkungan seperti memilah sampah, mendaur ulang sampah organik menjadi pupuk yang menghasilkan karya yang bermanfaat. Sekolah juga mempunyai kegiatan aksi rutin guna membentuk karakter peserta didik yaitu kegiatan SEMUTLIS (sepuluh menit untuk lingkungan sekolah) dan kegiatan jum'at bersih, kegiatan tersebut dilaksanakan secara konsisten setiap harinya untuk kegiatan jum'at bersih dilaksankan setelah melakukan kegiatan senam sehat. Selain kegiatan aksi rutin sekolah juga memanfaatkan kegiatan ekstrakurikuler yang terkait dengan pengelolaan lingkungan hidup yaitu BSC (Bodon sains club), labskill, dan dokter kecil, kegiatan tersebut menghasilkan karya yang bermanfaat bagi sekolah yaitu peserta didik diajarkan mendaur ulang sampah organik dan praktek membuat karya nyata atau kerajinan tangan yang berbahan dasar barang bekas. Karya tersebut kemudian dikomunikasikan melalui majalah dinding sekolah atau di pajang di dinding kelas. Implementasi kegiatan berbasis partisipatif melibatkan pihak luar dalam pengetahuan yang berkaitan dengan lingkungan hidup seperti DLH (Dinas Lingkungan Hidup), UPT, Kampus-kampus, ibu-ibu aisiyah. SD Muhammadiyah Bodon juga menyediakan sarana prasarana yang ramah lingkungan untuk mendukung pembelajaran pendidikan lingkungan hidup. Pelaksanaan tersebut juga didukung dengan ketersediaan pengelolaan dan perawatan sarana prasarana yang ramah lingkungan seperti tersedianya tempat sampah terpisah, ruang terbuka hijau, serta melakukan perawatan biopori, komposter dan kantin yang sehat dan ramah lingkungan. tersedinya sarana dan prasarana yang ramah lingkungan tersebut mendukung pembelajaran lingkungan disekolah karena peserta didik mendapatkan pengalaman secara nyata. Upaya kantin sehat dan ramah lingkungan juga mendukung terlaksananya pendidikan lingkungan hidup.

3. Evaluasi implementasi program adiwiyata di SD Muhammadiyah Bodon Kotagede

Evaluasi pengelolaan lingkungan hidup untuk mengatasi permasalahan lingkungan yang ada saat pembelajaran. Evaluasi biasanya dilakukan seminggu sekali untuk melakukan rapat atau workshop kegiatan dilaksanakan agar mengetahui kekurangan apa saja saat pembelajaran. Tim evaluasi dalam melakukan evaluasi melibatkan kepala sekolah, guru, dan tim adiwiyata sekolah untuk mengevaluasi program-program yang ada. 4. Faktor Pendukung Pelaksanaan Program Adiwiyata dalam Pembentukan Karakter Peduli Lingkungan.

Faktor pendukung dalam pelaksanaan program adiwiyata yaitu sekolah mengadakan pembiasaan kegiatan yang berbasis lingkungan, serta pihak sekolah bekerjasama dengan stakeholder, paguyuban wali murid, masayarakat, lembaga terkait disekitar sekolah daan instansi yang terkait lingkungan sekolah seperti PKU, Puskesmas, Ibu-ibu Aisiyah, dll. Untuk pembiyayaan perawatan lingkungan sekolah sudah juga memiliki anggaran yang cukup dan sudah diatur dalam RKAS untuk mendukung pelaksanaan program adiwiyata jadi semua sudah terpenuhi. Selain itu faktor pendukung lainnya yaitu lingkungan sekolah yang memungkinkan untuk dijadikan ruang terbuka hijau meskipun tidak terlalu luas dengan kerjasama dan kreatifitas maka sekolah dapat menciptakan suasana sejuk dan asri. Selain lingkungan yang mendukung fasilitas yang 
mwndukung seperti Sarana prasarana yang ramah lingkungan seperti Tempat sampah terpisah, Komposter, Biopori, Kantin sehat dan ramah lingkungan sehingga mendukung pelaksanaan program adiwiyata dalam pembentukan karakter peduli lingkungan.

5. Faktor Penghambat Pelaksanaan Program Adiwiyata dalam Pembentukan Karakter

Peduli Lingkungan Adapun kendala dalam pelaksanaan pendidikan karakter peduli lingkungan yaitu masih kurangnya kesadaran diri untuk melaksankan kegiatan peduli lingkungan, kurangnya personil dalam perawatan sarana prasarana, kurangnya rasa kebersamaan antara warga sekolah. Faktor penghambat lainnya yaitu sarana dan prasarana yang sudah lengkap akan tetapi masih ada beberapa yang dibutuhkan untuk mendukung pelaksanaan pendidikan lingkungan hidup seperti lahan untuk menanam tanama hijau karena sekolah hanya mempunyai lahan yang kecil.

\section{Pembahasan}

Perencanaan,pelaksanaan dan evaluasi Program Adiwiyata Dalam Pembentukan Karakter Peduli Lingkungan.

1. Perencanaan Program Adiwiyata Dalam Pembentukan Karakter Peduli Lingkungan

Berdasarkan hasil penelitian, perencanaan program adiwiyata dalam pembentukan karakter peduli lingkungan yaitu salah satunya dengan mengintegrasikan melalui visi dan misi sekolah. SD Muhammadiyah Bodon Kotagede merumuskan visi dan misi sekolah dengan kebijakan berwawasan lingkungan, kebijakan tersebut disosialisasikan kepada seluruh warga sekolah melalui rapat dengan melibatkan seluruh warga sekolah dan wali murid secara aktif yang biasanya dilakukan setiap 2 bulan sekali. Selain itu sekolah juga merancang struktur kurikulum dan ketuntasan minimal belajar yang berkaitan dengan lingkungan hidup. Guru merancang pembelajaran terkait dengan pendidikan lingkungan hidup, namun tidak semua mata pelajaran sudah terintegrasi dengan pendidikan lingkungan hidup karena ada mata pelajaran yang tidak memuat pendidikan lingkungan hidup untuk itu harus menyesuaikan dengan tema yang akan diajarkan.

2. Pelaksanaan Program Adiwiyata Dalam Pembentukan Karakter Peduli Lingkungan.

Berdasarkan hasil penelitian pelaksanaan pembentukan karakter peduli lingkungan mengintegrasikan dalam mata pelajaran yang dilakukan guru dengan cara mengintegrasikan nilai peduli lingkungan dalam semua mata pelajaran, guru mengembangkan pembelajaran yang aktif. Nilai-nilai peduli lingkungan dilaksanakan dan disampaikan dalam pengintegrasian mata pelajaran memeperhatikan keterkaitan anatara KI dan KD dengan nilai dan indicator untuk menentukan nilai pendidikan peduli lingkungan yang akan dikembangkan. Guru mengembangakan proses pembelajaran yang aktif sehingga peserta didik dapat secara langsung mempraktikan nilai dan sikap peduli lingkungan. sekolah juga mempunyai kegiatan aksi atau rutin yang dilaksanakan untuk membentuk karakter peduli lingkungan peserta didik yaitu kegiatan SEMUTLIS dan Jum'at bersih secara rutin. Kegiatan SEMUTLIS dilaksankan secara konsisten setiap hari sebelum pembelajaran dimulai, sedangkan kegiatan Jum'at bersih dilaksanakan secara konsisten setiap hari jum'at setelah kegiatan senam sehat yang dilakukan oleh seluruh warga sekolah. Kegiatan rutin sekolah dilaksanakan dengan mengoptimalkan sarana dan prasarana yang ada disekolah untuk mecapai tujuan pendidikan yang diharapkan.

3. Evaluasi Program Adiwiyata Dalam Pembentukan Karakter Peduli Lingkungan

Berdasarkan hasil penelitian di SD Muhammadiyah bodon evaluasi dalam pelaksanaan pendidikan karakter peduli lingkungan diantaranya dilakukan rapat rutin 
setiap minggu. Kegiatan dilaksanakan agar mengetahui kekurangan apa saja saat pembelajaran. Tim evaluasi dalam melakukan evaluasi melibatkan kepala sekolah, guru, dan tim adiwiyata sekolah untuk mengevaluasi program-program yang ada.

Faktor Pendukung Pelaksanaan Program Adiwiyata dalam Pembentukan Karakter Peduli Lingkungan Faktor pendukung dalam pelaksanaan program adiwiyata yaitu sekolah mengadakan pembiasaan kegiatan yang berbasis lingkungan, serta pihak sekolah bekerjasama dengan stakeholder, paguyuban wali murid, masayarakat, lembaga terkait disekitar sekolah daan instansi yang terkait lingkungan sekolah seperti PKU, Puskesmas, Ibu-ibu Aisiyah, dll. Untuk pembiyayaan perawatan lingkungan sekolah sudah juga memiliki anggaran yang cukup dan sudah diatur dalam RKAS untuk mendukung pelaksanaan program adiwiyata jadi semua sudah terpenuhi. Selain itu faktor pendukung lainnya yaitu lingkungan sekolah yang memungkinkan untuk dijadikan ruang terbuka hijau meskipun tidak terlalu luas dengan kerjasama dan kreatifitas maka sekolah dapat menciptakan suasana sejuk dan asri. Selain lingkungan yang mendukung fasilitas yang mwndukung seperti Sarana prasarana yang ramah lingkungan seperti Tempat sampah terpisah, Komposter, Biopori, Kantin sehat dan ramah lingkungan sehingga mendukung pelaksanaan program adiwiyata dalam pembentukan karakter peduli lingkungan.

Faktor Penghambat Pelaksanaan Program Adiwiyata dalam Pembentukan Karakter Peduli Lingkungan Adapun kendala dalam pelaksanaan pendidikan karakter peduli lingkungan yaitu masih kurangnya kesadaran diri untuk melaksankan kegiatan peduli lingkungan, kurangnya personil dalam perawatan sarana prasarana, kurangnya rasa kebersamaan antara warga sekolah. Faktor penghambat lainnya yaitu sarana dan prasarana yang sudah lengkap akan tetapi masih ada beberapa yang dibutuhkan untuk mendukung pelaksanaan pendidikan lingkungan hidup seperti lahan untuk menanam tanama hijau karena sekolah hanya mempunyai lahan yang kecil.

\section{SIMPULAN}

Berdasarkan hasil penelitian yang telah dilakukan di SD Muhammadiyah Bodon Kotagede maka dapat disimpulkan sebagai berikut.

1. Perencanaan, pelaksanaan dan evaluasi program adiwiyata dalam pembentukan karakter peduli lingkungan di SD Muhammadiyah Bodon Kotagede dapat diambil kesimpulan bahwa kebijakan berwawasan lingkungan dengan mengintegrasikan pada visi, misi sekolah, serta mengintegrasikan pada struktur kurikulum yang sudah terintegrasi pendidikan lingkungan hidup sekolah menggunakan kurikulum 2013. Pengintegrasian tersebut kemudian di sosialisasikan kepada seluruh warga sekolah, guru juga mengajak peserta didik belajar diluar kelas agar mendapatkan pengalaman belajar secara nyata. Sekolah juga mengembangkan kegiatan ekstrakurikuler yang dikembangkan untuk pembelajarn pendidikan lingkungan hidup antara lain BSC (Bodon sains club), labskill, SD Muhammadiyah Bodon Kotagede dalam pelaksanaan program adiwiyata sebagai pembentukan karakter peduli lingkungan memiliki beberapa evaluasi untuk memperlancar berjalannya program adiwiyata, sekolah melaksanakan evaluasi satu minggu sekali yang biasanya di sebut workshop.

2. Faktor pendukung dan penghambat dalam pelaksanaan program adiwiyata dalam pembentukan pendidikan karakter yaitu sekolah mengadakan pembiasaan kegiatan berbasis lingkungan, serta warga sekolah yang bekerja sama untuk menjalakan kemauan pelaksanaan program adiwiyata. Serta pihak sekolah yang bekerja sama dengan steakholder, paguyuban wali peserta didik, mitra sekolah seperti 
puskesmas, PKU, ibu-ibu aisiyah, warga sekitar sekolah serta instansi yang terkait dalam pelaksanaan pendidikan lingkungan hidup. Faktor pendukung lainnya yaitu anggaran yang memadai dan sarana prasarana pendukung yang ramah lingkungan. adapun kendala atau faktor penghambat dalam pelaksanaan pendidikan lingkungan hidup yaitu kurangnya rasa kebersamaan dalam melaksanakan kegiatan lingkungan hidup sehingga hanya sebagian warga sekolah yang ikut aktif dalan pelaksanaan lingkungan hidup. Sekolah masih kekurangan lahan untuk proses menanam tumbuhan hijau.

\section{DAFTAR PUSTAKA}

Hamzah, S. (2013). Pendidikan Lingkungan. Bandung: PT Refika Aditama.

Hidup, K. L. (2011). Panduan Adiwiyata Sekolah Peduli dan Berbudaya Lingkungan. Jakarta Timur.

Kemendiknas. (2010). Nilai-nilai yang Dikembangkan dalam Pendidikan Budaya dan Karakter Bangsa.

Kementrian Pendidikan Nasional.2010. Pengembangan Pendidikan Budaya dan Karakter

Bangsa. Jakarta: Badan Penelitian dan Pengembangan Pusat Kurikulum

Maryani, I. (2014). Evaluasi Pelaksanaan Program Sekolah Adiwiyata Ditinjau dari Aspek Kegiatan Partisipatif di SDN Ungaran 1 Yogyakarta. Jurnal Pemikiran dan Pengembangan Sekolah Dasar, I, 225-229

Trisnaningsih,S,A.,\& Maryani, I. (2018). Pengembangan Komik Ipa Berbasis Karakter Peduli Lingkungan Pada Materi Struktur Dan Fungsi Bagian Tumbuhan (Uji Coba Siswa Kelas IV SD Muhammadiyah Kleco). Fundamental Pendidikan Dasar, 1, 1828

Nasional, K. P. (2010). Pengembangan Pendidikan Budaya dan Karakter Bangsa. Jakarta.

Nurdiyati, D., \& Pambudi, D. I. (2018). Implementasi Program Adiwiyata di SD Negeri Bhayangkara Yogyakarta. Jurnal Fundamental Pendidikan Dasar, I, 45-54.

Rohman, A. (2009). Memahami Pendidikan dan Ilmu Pendidikan. Yogyakarta: Laksbang Mediatama Yogyakarta.

Setiani, N. (2013). Pendidikan Karakter Peduli Lingkungan melalui Program "Green Environment" di SMP Ar-ridho Kota Semarang. Semarang: UNNES

Undang-Undang RI Nomor 36 Tahun 2009 tentang Kesehatan

Undang-Undang Republik Indonesia Nomor 20 Tahun 2009 Tentang Perlindungan dan Pengembangan Lingkungan Hidup

Widyaningrum, R. (2016). Pembentukan Karakter Peduli Lingkungan Siswa Sekolah Dasar Peduli dan Berbudaya Lingkungan. Jurnal Widyawacana, XI, 105-108.

Widodo, H. (2017). Budaya Sekolah Adiwiyata (Studi Kasus di SD Muhammadiyah Bodon, Bantul, Yogyakarta). Tajdidukasi, VII, 6. 